\title{
HYPOTHALAMIC HYPOTHYROIDISM IN A NEWBORN WITH CLASSIC GALACTOSEMIA: CASE REPORT
}

\author{
Ivana UNIC SABASOV*, Vjekoslav KRZELJ, Veselin SKRABIC, Maja TOMASOVIC, \\ Radenka KUZMANIC SAMIJA
}

Department of Pediatrics, University

Hospital Split, Split, Croatia

${ }^{*}$ Corresponding author: iunic@kbsplit.hr

Tel.: + 38521556287

Fax: + 38521556590

Received: February 2, 2015

Accepted: April 16, 2015

\begin{abstract}
Objective - To report a rare case of classic galactosemia and hypothalamic hypothyroidism. Case report - A male newborn presented with failure to thrive, prolonged cholestatic jaundice, sepsis and hypothyroidism. Hydration, empiric antibiotics and L-thyroxine treatment were started. Since classic galactosemia had been suspected and confirmed, a galactose-restricted diet was commenced. The patient's health status improved, including the fast recovery of the thyroid function tests. L-thyroxine dosage was decreased two weeks after starting the therapy and completely stopped two months after starting the galactose-restricted diet. Conclusion - Further investigations are necessary to establish whether such patients require treatment with L-thyroxine or a galactose-restricted diet is sufficient. It may be useful
\end{abstract}

Key words: Galactosemia - Hypothalamic to perform thyroid function tests also in infants diagnosed with classic disease • Hypothyroidism • Newborn.

\section{Introduction}

Classic galactosemia (OMIM 230400) is an autosomal recessive disorder of carbohydrate metabolism, due to deficiency of the galactose-1-phosphate-uridyltransferase (GALT) enzyme. GALT enzyme deficiency results from a mutation in the gene on chromosome $9 \mathrm{p} 13$ and leads to accumulation of galactose and metabolites (galactose-1-phosphate, and galactitol) in different organs. Most patients present with feeding difficulties, failure to thrive, liver disease, cataracts, encephalopathy and sepsis. Early diagnosis and treatment improve the prognosis in patients with classic galactosemia (1-3). Regarding endocrine abnormalities in classic galactosemia, female hypergonadotropic hypogonadism has often been reported (4-7). Other endocrine system disturbances have rarely been described. We present a male newborn with classic galacto- semia and transitory hypothalamic hypothyroidism, treated with a galactose-restricted diet and L-thyroxine.

\section{Case report}

The male infant was born at term from the second normal pregnancy and delivery. The birth weight was $4400 \mathrm{~g}$, the length of $54 \mathrm{~cm}$ and head circumference $38 \mathrm{~cm}$. He was admitted to our hospital at the age of 8 days with the weight of $4000 \mathrm{~g}$ for cholestatic jaundice and hepatomegaly. There were no clinical signs of hypothyroidism or cataracts. The first laboratory findings showed an unconjugated hyperbilirubinemia (total serum bilirubin 352, conjugated 24.6 and unconjugated $328 \mu \mathrm{mol} / \mathrm{l}$ ) and the rest of the biochemical findings were within the reference ranges. $\mathrm{He}$ was treated with intravenous fluids, empiric antibiotics and phototherapy. At the age of 
11 days, no weight gain was observed and the laboratory findings showed further elevation of the conjugated fraction of bilirubin (total serum bilirubin 138, conjugated $91 \mu \mathrm{mol} / \mathrm{l}$ ) and modest hypertransaminasemia (aspartate transaminase 47 , reference range 6-34 $\mathrm{U} / \mathrm{l}$; alanine transaminase 48 , reference range 5-20 U/l). At the age of 22 days, the patient, whose weight was $4400 \mathrm{~g}$, became lethargic with further progression of hepatomegaly, incipient ascites and increased head circumference. Brain sonography showed increased white matter volume and echogenicity. MR of brain showed multiple small hyperintense lesions in the cerebral white matter on T2weighted images. Urine reducing substances were positive and due to a suspicion of galactosemia, galactose-free formula was started. The infant's condition rapidly improved. The diagnosis of galactosemia was confirmed by the high levels of galactose-1-phosphate in the erythrocytes (3.0, reference range 0 $0.3 \mathrm{mg} / \mathrm{dl})$ and highly reduced GALT activity $(0 \mu \mathrm{mol} / \mathrm{h} / \mathrm{g} \mathrm{Hb}$, reference range $20-35$ $\mu \mathrm{mol} / \mathrm{h} / \mathrm{g} \mathrm{Hb})$. Both parents' GALT activities (mother's GALT 10.7 and father's GALT $11.3 \mu \mathrm{mol} / \mathrm{h} / \mathrm{g} \mathrm{Hb}$ ) were within the limits for heterozygous of classic galactosemia (9$14 \mu \mathrm{mol} / \mathrm{h} / \mathrm{g} \mathrm{Hb})$. DNA analysis revealed that the father is heterozygous for Q188R and the mother for K285N mutation. Both mutations are known as severe mutations. The patient is a compound heterozygote with Q188R/K285N gene mutations. The thyroid function tests obtained during the first week of admission showed low triiodothyronine ( $\mathrm{T}_{3} 0.4$, reference range $\left.1.1-4 \mathrm{nmol} / \mathrm{l}\right)$, low thyroxine $\left(\mathrm{T}_{4} 42\right.$, reference range 77-205 $\mathrm{nmol} / \mathrm{l})$ and normal thyroid stimulating hormones (TSH 3.75, reference range 0.4-5 $\mathrm{mU} / \mathrm{l})$ revealing hypothyroidism. Other pituitary hormones were not measured. Thyroid binding globuline (TBG) was normal (22.5, reference range $12-30 \mathrm{mg} / \mathrm{l})$ as well as anti-thyroid peroxidase, thyrotropin recep- tor (TRAbs) and thyroglobulin antibodies. The thyrotropin-releasing hormone (TRH) test suggested hypothalamic hypothyroidism with delayed TSH response (60 minute value higher than at 15 minutes) (Table 1).

\begin{tabular}{ll}
\hline Table 1 TRH test results & \\
\hline Time (minutes) & TSH (mIU/l) \\
\hline 0 & 0.7 \\
15 & 2.4 \\
30 & 15.8 \\
Ili 60 & 16 \\
\hline
\end{tabular}

Thereafter, therapy with L-thyroxine 25 $\mu \mathrm{g}$ daily $(6.25 \mu \mathrm{g} / \mathrm{kg})$ was commenced at the age of 11 days. The next check-up of thyroid function was seven days after initiation of galactose-free formula, when we observed laboratory euthyreosis. Subclinical hyperthyroidism $\left(\mathrm{T}_{3} 2.1, \mathrm{~T}_{4} 124 \mathrm{nmol} / \mathrm{l}\right.$, TSH 0.2 $\mathrm{mU} / \mathrm{l}$ ) was observed 14 days after initiation of galactose-restricted diet. Thereafter, the dose of L-thyroxine was gradually decreased and stopped two months after starting the galactose-free formula. At follow-up at 12 months, the infant was growing and developing normally.

\section{Discussion}

In classic galactosemia, female hypergonadotropic hypogonadism has already been recognised. Other endocrine disorders have been reported incidentally and are not fully understood (4-7). In this report, a male newborn is presented with classic galactosemia and central hypothyroidism $(\mathrm{CH})$. We suspected galactosemia in our patient for several reasons: no weight gain, prolonged jaundice, sepsis, progression of hepatomegaly and enlargement of head circumference. Most cases of galactosemia, which has a prevalence of about 1 in 23000 to 1 in 44000 in Europe, are detected through newborn screening of 
GALT enzyme activity and/or galactose-1 phosphate concentration in red blood cells (8). There is no such screening in Croatia. This case also emphasizes the importance of early recognition of galactosemia, as delay in diagnosis could compromise the patient's health. $\mathrm{CH}$ is a rare form of hypothyroidism. The prevalence of $\mathrm{CH}$ is estimated to be around 1 in 80000 to 1 in 120000 individuals (9-10). It develops due to insufficient thyroid gland stimulation by TSH, emerging from hypothalamic (congenital tertiary hypothyroidism) and/or pituitary dysfunction (congenital secondary hypothyroidism). Congenital $\mathrm{CH}$ most commonly results from mutations in genes involved in pituitary organogenesis (PROP, LHX2, LHX3) or in the differentiation of a particular endocrine cell lineage (PIT1). Special attention has to be paid to congenital primary hypothyroidism $(\mathrm{CPH})$. The incidence of $\mathrm{CPH}$, as detected through newborn screening, is approximately 1 per 4000 births (11). The typical manifestations of $\mathrm{CPH}$ are jaundice, macroglossia, a coarse cry, failure to thrive, sepsis, retarded growth, umbilical hernia, hypotonia, and cretenism (11-12). The most obvious characteristics of $\mathrm{CH}$ that are not present in $\mathrm{CPH}$ are association with pituitary hormone deficiency, absence of goitre, decreased $\mathrm{T}_{4}$ or $\mathrm{fT}_{4}$ levels in the presence of low or inappropriately normal TSH levels, and always the absence of antithyroid antibodies (11). In neonates, $\mathrm{CH}$ may be identified by screening program based on concomitant TSH and total $\mathrm{T}_{4} / \mathrm{fT}_{4}$ measurements and thereafter an abnormal TSH response to TRH testing (9). In our patient, the thyroid function tests were done due to prolonged jaundice. The patient had low $\mathrm{T}_{3}$ and $\mathrm{T}_{4}$, normal $\mathrm{TSH}$, normal TBG and normal antithyroid antibodies, all suggesting $\mathrm{CH}$. The hypothyroidism in this newborn could not be detected by the Croatian newborn screening program for detection of congenital hypothyroidism, since the program is based on the measurement of TSH alone. We performed the TRH test to differentiate hypothalamic from pituitary hypothyroidism. The TRH test results suggested hypothalamic hypothyroidism, as a delayed TSH response was observed. The treatment with L-thyroxine rapidly improved the thyroid function test results. Moreover, after initiation of a galactose-restricted diet, we observed subclinical hyperthyroidism. Our observations are similar to the findings of Berger et al. (5) who suggested that $T_{4}$ normalized due to an initiated galactose-restricted diet. These authors hypothesized that the low $\mathrm{T}_{4}$ resulted either from disturbances in the hypothalamic control of thyroid function or because of changes in the peripheral metabolism of $\mathrm{T}_{4}$. Von Petrykowski (6) report on two infants with classic galactosemia and hypothyroidism. It remains to be examined how often dysfunction of the hypothalamopituitary (HP) axis occurs in patients with classic galactosemia. Berger et al. (5) suggested that low thyroid hormones might not implicate diagnosis of hypothyroidism and that treatment with L-thyroxine is not required. It is questionable whether one should commence early treatment of hypothyroidism as soon as hypothyroidism is suspected or not until the screening program results are known. In addition, it would be interesting to discover whether L-thyroxine quickens the process of recovery of the HP axis in patients on a galactose-restricted diet similar to its action in the resolution of cholestasis and hepatosplenomegaly (7). It may be useful also to perform thyroid function tests in infants diagnosed with classic galactosemia. Finally, we strongly advocate the introduction of a screening program for galactosemia in our country.

\section{Conclusions}

We present a male newborn with classic galactosemia and transitory hypothalamic 
hypothyroidism, treated with a galactoserestricted diet and L-thyroxine. It has to be established whether such patients require treatment with L-thyroxine or if a galactoserestricted diet is sufficient.

Authors' contributions: Conception and design: IUŠ and VK; Acquisition, analysis and interpretation of data: IUŠ, VK, VŠ, MT and RKŠ; Drafting the article IUŠ and VK; Revising it critically for important intellectual content: IUŠ and VK.

Conflict of interest: The authors declare that they have no conflict of interest.

\section{References}

1 Tang M, Facchiano A, Rachamadugu R, Calderon F, Mao R, Milanesi L, et al. Correlation assessment among clinical phenotypes, expression analysis and molecular modeling of 14 novel variations in the human galactose-1-phosphate uridylyltransferase gene. Hum Mutat. 2012;33(7):1107-15.

2 Bosch AM. Classical galactosemia revisited. J Inherit Metab Dis. 2006;29:516-25.

3 Bosch AM, Grootenhuis MA, Bakker HD, Heijmans HSA, Wijburg FA, Last BF. Living with classical galactosemia: Health-related quality of life consequences. Pediatrics. 2004;113:423-8.

4 Rubio-Gozalbo ME, Panis B, Zimmermann LJI, Spaapen LJ, Menheere PPCA. The endocrine sys- tem in treated patients with classical galactosemia. Mol Genet Metab. 2006;89:316-22.

5 Berger HM, Vlasveld MB, Van Gelderen $\mathrm{HH}$, Ruys JH. Low serum thyroxine concentrations in babies with galactosemia. J Pediatr. 1983;103:9302.

6 Von Petrykowsky W. Galactosemia and hypothyroidism. J Pediatr. 1984;105:509.

7 Karnsakul W, Sawathiparnich P, Nimkarn S, Likitmaskul S, Santiprabhob J, Aanpreung P. Anterior pituitary hormone effects on hepatic functions in infants with congenital hypopituitarism. Ann Hepatol. 2007;6:97-103.

8 Senemar S, Ganjekarimi AH, Senemar S, Tarami B, Bazrgar M. The prevalence and clinical study of galactosemia disease in a pilot screening program of neonates, Southern Iran. Iranian J Publ Health. 2011;40:99-104.

9 Gupta V, Lee M. Central hypothyroidism. Indian J Endocrinol Metab. 2011;15:S99-S106.

10 Persani L. Clinical review: Central hypothyroidism: pathogenic, diagnostic, and therapeutic challenges. J Clin Endocrinol Metab. 2012;97:3068-78.

11 Delange F. Screening for congenital hypothyroidism used as an indicator of the degree of iodine deficiency and of its control. Thyroid. 1998;8:118592.

12. LeFranchi SH. Newborn screening strategies for congenital hypothyroidism: an update. J Inherit Metab Dis. 2010;33:S225-S33. 